\title{
What Triggers Differential DNA Methylation of Genes and TEs: Contribution of Body Methylation?
}

\author{
S. INAGAKI AND T. KAKUTANI \\ Department of Integrated Genetics, National Institute of Genetics, \\ Mishima, Shizuoka 411-8540, Japan \\ Correspondence: tkakutan@nig.ac.jp
}

\begin{abstract}
Transposable elements (TEs) are epigenetically silenced with extensive DNA methylation. The silent epigenetic marks should, however, be excluded from active genes. By genetic approaches, we study mechanisms to remove the heterochromatin marks from transcribed genes. Based on our observations on control of TE transcription, we propose a possible trigger for the TE-specific accumulation of DNA methylation. A critical difference between TEs and genes could be their responses to the DNA methylation in the internal part of transcribed regions. When their internal region is methylated, genes are still transcribed, but TEs could be silenced, which may reflect the obligatory position of every critical cis-acting element within the TE itself. This initial difference of TEs and genes will be amplified by positive feedback loops to stabilize active or silent states. Thus, the mechanisms to accumulate heterochromatin marks within transcribed regions could provide a trigger to induce differential DNA methylation between genes and TEs.
\end{abstract}

In plant genomes, DNA methylation of transposable elements (TEs) is important for genome stabilization and appropriate expression of cellular genes near TEs (Kakutani et al. 2004; Lippman et al. 2004; Chan et al. 2005; Huettel et al. 2006; Saze and Kakutani 2007; Mirouze et al. 2009; Tsukahara et al. 2009). Genome-wide analyses of DNA methylation have revealed that TEs are heavily methylated in cytosines in all three sequence contexts: $\mathrm{CG}, \mathrm{CHG}$, and $\mathrm{CHH}(H$ can be $\mathrm{A}, \mathrm{T}$, or $\mathrm{C})$. On the other hand, the methylation level is much lower in genes and the genic methylation is limited to CG sites (Zhang et al. 2006; Zilberman et al. 2007; Cokus et al. 2008; Lister et al. 2008). A central question is what triggers the differential DNA methylation between genes and TEs.

Whereas methylation in CG sites is maintained by the maintenance CG methyltransferase MET1, TE-specific non-CG methylation is connected to other epigenetic marks for silent chromatin. Methylation at $\mathrm{CHG}$ sites depends on methylation of lysine 9 in histone $\mathrm{H} 3$ (H3K9me) (Jackson et al. 2002; Malagnac et al. 2002). H3K9me is an epigenetic mark of silent chromatin found in diverse organisms, including animals and fungi. TEs can also be methylated at asymmetric $\mathrm{CHH}$ sites and that is generally associated with small RNA. Small RNA is also a hallmark of silent chromatin conserved in diverse organisms (Grewal and Elgin 2007). In plants, the mechanisms controlling heterochromatin by small RNA have been extensively studied by genetic characterization of RNAdirected DNA methylation (RdDM). RdDM is an intriguing phenomenon first observed in tobacco, in which double-stranded RNA induces de novo DNA methylation of identical sequences (Wasseneger et al. 1994; Mette et al. 2000). RdDM can induce de novo DNA methylation in all three sequence contexts. Genetic screening of Arabidopsis has led to identification of factors involved in RdDM, which includes the de novo DNA methyltransferase DRM2, the chromatin remodeling factor DRD1, as well as additional components of RNA interference (RNAi) and RNA polymerase complexes (Matzke et al. 2009; Law and Jacobsen 2010; Haag and Pikaard 2011).

One important feature of silent chromatin is that interactions among the various epigenetic marks generate positive feedback loops. $\mathrm{CHG}$ sites are methylated by the DNA methyltransferase CMT3 (chromomethylase 3). CMT3 activity depends on $\mathrm{H} 3 \mathrm{~K} 9$ me at the target locus. H3K9me is catalyzed by the histone methyltransferase KYP/SUVH4 and its activity depends on methylation at CHG sites (CHGme) (Johnson et al. 2007; Inagaki et al. 2010). The interdependence of $\mathrm{H} 3 \mathrm{~K} 9 \mathrm{me}$ and $\mathrm{CHGme}$ creates a positive feedback loop. Likewise, a positive feedback loop may operate between DNA methylation and small RNA. DNA methylation, especially at $\mathrm{CHH}$ sites, depends on the RdDM machinery. The generation of small RNA, on the other hand, depends on the DNA methyltransferase DRM2 (Zilberman et al. 2004; Henderson et al. 2010). These positive feedback loops would explain how chromatin silencing is enhanced, spread, and stabilized, but it does not clarify the difference that initially triggers the differential methylation of TEs and genes.

RdDM would be an important mechanism to specifically target heterochromatin to TEs. Rearrangements and nested insertions of TEs often generate tandem direct repeats and inverted repeats. In addition, a TE generally has inverted or direct repeats in the terminal regions. These repeats could be templates for small RNA and would result in DNA methylation by the RdDM process (Martienssen 2003). In mutants of RdDM machinery, however, only a few TEs are derepressed transcriptionally 
(Lippman and Martienssen 2004; Xie et al. 2004; Huettel et al. 2006). That is in contrast to the effects of met 1 mutants or mutants defective in the chromatin remodeler $D D M 1$ that show derepression of many more TEs (Lippman et al. 2004). RdDM mutants generally affect short TEs and their derivatives, such as short interspersed elements (SINEs) (Lippman and Martienssen 2004; Herr et al. 2005) and solo long terminal repeats (LTRs) (Huettel et al. 2006). Genome-wide DNA methylation analyses, as well as small RNA surveys, also identify short TEs as targets of RdDM (Tran et al. 2005; Lee et al. 2012). The RdDM component NRPE1 localizes over the entire sequence of short TEs but localizes specifically in terminal regions of long TEs (Zhong et al. 2012). These results suggest that the internal heterochromatin of long TEs, which depends on MET1 and DDM1, does not depend on RdDM. Length seems to be an important parameter for epigenetic control of TEs and their derivatives.

In the following part of this article, we discuss transcriptional response of genes and TEs in the contexts of epigenetic modifications and sequence length and propose a possible mechanism that triggers their differential DNA methylation. The critical difference between genes and TEs could be their transcriptional responses to the change in DNA methylation within the transcribed region. The model that we propose might also be related to another question: What is the role of gene-body methylation?

\section{INTERNAL REGIONS OF LONG TRANSCRIBED SEQUENCES ACCUMULATE CG METHYLATION}

Unlike DNA methylation in TEs and repeats, genic DNA methylation is limited to CG sites (Cokus et al. 2008; Lister et al. 2008). This gene-body CG methylation is high in the central part of genes, and $5^{\prime}$ and $3^{\prime}$ terminal regions are not typically methylated. Interestingly, long genes have more body methylation than short genes (Inagaki et al. 2010; Takuno and Gaut 2012).

Counterintuitively, gene-body methylation is higher in transcribed genes than in untranscribed genes. The basis for this association is not clear. Loss of CG methylation in met 1 mutation does not substantially affect the expression of body-methylated genes (Zhang et al. 2006). Thus, the correlation is not attributable to an effect of body methylation on transcription. Rather, gene-body methylation could be the consequence of transcription (see further discussion below).

The mechanism for targeting body methylation is not clear. In addition, the role of gene-body methylation is not clear either. Interestingly, gene-body methylation excludes H2A.Z (Zilberman et al. 2008). H2A.Z is a histone variant conserved among eukaryotes and controls transcription in diverse manners. Although H2A.Z distribution is affected by a met 1 mutation, disruption of H2A.Z genes does not substantially affect gene-body methylation (Zilberman et al. 2008; Coleman-Derr and Zilberman 2012). Therefore, H2A.Z is not the upstream factor determining the distribution of gene-body methylation. Rather, gene-body methylation, which may be controlled by transcription, seems to be the upstream factor.

\section{INTERNAL REGIONS OF LONG TRANSCRIBED SEQUENCES ACCUMULATE CHGME AND H3K9ME WHEN THE IBM1 HISTONE DEMETHYLASE IS NONFUNCTIONAL}

The body of long genes also has the potential to accumulate TE-specific epigenetic marks, such as H3K9me and CHGme. By a genetic screen of Arabidopsis mutants showing ectopic cytosine methylation in a genic region, we identified a novel H3K9 demethylase gene IBMI (increase in bonsai methylation 1 ). The $i b m 1$ mutation induces ectopic H3K9me and CHGme in thousands of genes (Saze et al. 2008; Miura et al. 2009; Inagaki et al. 2010). Both $\mathrm{H} 3 \mathrm{~K} 9 \mathrm{me}$ and $\mathrm{CHGme}$ are TE-specific epigenetic marks in the wild type, but they are found in genes in the $i b m 1$ mutant. The $i b m 1$ mutation affects constitutively expressed genes and long genes. Central regions of transcription units are affected, whereas $5^{\prime}$ and $3^{\prime}$ terminal regions are not affected. This spectrum of $i b m l$-affected genes is strikingly similar to that of gene-body methylation at CG sites in wild-type plants (Miura et al. 2009; Inagaki et al. 2010). This similarity suggests that genebody CG methylation may have a causative relationship with $\mathrm{CHGme}$ that is revealed when the function of $\mathrm{H} 3 \mathrm{~K} 9$ demethylase IBM1 is masked (Saze and Kakutani 2011). Again, transcription could be a common upstream factor to induce the accumulation of these marks within the transcription unit.

\section{TRANSCRIPTION OF GENES IS AFFECTED BY DNA METHYLATION IN PROMOTERS BUT NOT IN INTERNAL REGIONS}

Notably, increased CHGme and H3K9me in the ibm 1 mutant does not substantially affect the expression of the target genes. Similarly, the loss of CG methylation in met 1 does not affect the expression of most body-methylated genes (Zhang et al. 2006). These results indicate that DNA methylation and $\mathrm{H} 3 \mathrm{~K} 9$ me in internal regions generally do not affect the transcription of genes.

Although DNA methylation in internal regions has a limited effect on expression, DNA methylation at promoters or $5^{\prime}$ terminal regions is associated with gene silencing. DNA methylation is found in the promoters of SDC and FWA genes and these genes are derepressed in mutants of DNA methyltransferases (Soppe et al. 2000; Kinoshita et al. 2004; Lippman et al. 2004; Henderson and Jacobsen 2008). Interestingly, promoters of these genes have features similar to short TEs and repeats (Lippman et al. 2004; Fujimoto et al. 2008; Henderson and Jacobsen 2008). In addition, changes of DNA methylation in TEs often affect expression of nearby genes (Huettel et al. 2006; Saze and Kakutani 2007). In summary, transcription of genes can be affected by DNA 
methylation in the promoter or even surrounding outside regions, but DNA methylation in internal regions does not affect the transcription of genes substantially.

\section{UNLIKE GENES, TRANSCRIPTION OF TES CAN BE AFFECTED BY DNA METHYLATION IN BOTH PROMOTER AND INTERNAL REGIONS}

In an Arabidopsis met1 mutant, a large number of TEs are up-regulated. These activated TEs include both promoter-methylated and body-methylated types, suggesting possible roles for both domains of methylation in TE silencing (Zhang et al. 2006).

Derepression of TEs is also found in cmt3 and kyp mutants. Importantly, this TE transcription decreases when these mutations are combined with an $i b m 1$ mutation (Inagaki et al. 2010). In the double mutants ibm 1-kyp or ibmlcmt3, H3K9me levels are increased in the central regions of TEs, which is associated with transcriptional silencing. This is in striking contrast to the $i b m 1$-induced increase of $\mathrm{H} 3 \mathrm{~K} 9 \mathrm{me}$ in gene bodies; although increased $\mathrm{H} 3 \mathrm{~K} 9 \mathrm{me}$ and CHGme in the transcribed region does not affect the transcription of genes, the internal heterochromatin marks affect transcription of these TEs.

Taken together, these observations are consistent with the idea that the silencing of TEs can be regulated by DNA methylation not only in the promoter but also in the internal region. What could be the basis for the difference between transcriptional responses of TEs and genes? An intact TE brings its cis-acting elements during transposition. Therefore, cis-acting elements critical for transcription, such as a methylation-sensitive enhancer, should be within a TE itself, often localizing in the transcribed regions (Fig. 1, bottom). The situation is different in genes, which can be controlled by enhancers that are further away from transcribed regions (Fig. 1, top). Genes evolve to coordinate transcription using surrounding cis-acting elements. In contrast, TEs have evolved to control their expression independently, so that the control works even after transposition to a different genomic environment.

\section{HYPOTHESIS}

Assumption 1. Transcription induces accumulation of $\mathrm{H} 3 \mathrm{~K} 9 \mathrm{me}$ and CHGme in the internal region of transcription unit for both TEs and genes.

Assumption 2. H3K9me and CHGme in the internal region inhibit transcription of TEs, but not genes.

Model. Transcription induces accumulation of H3K9me and DNA methylation in the internal region for both genes and TEs (Fig. 2, top). These modifications result in silencing of TEs but not genes (Fig. 2, middle). Genes remain transcribed, which induces active H3K9 demethylation by IBM1 (Fig. 2, bottom right). On the other hand, IBM1-induced H3K9 demethylation is not efficient in the silenced TEs. In silenced TEs, the H3K9me and CHGme enhance each other and spread to terminal regions including the promoter, making the TE silencing more robust and stable (Fig. 2, bottom left).

\section{HOW GENERAL?}

A key feature in the model that we propose is that body methylation could affect the transcription of TEs, because they should have promoter/enhancer elements within the TE itself. This seems a general feature of TEs, but the situation might differ among TEs because their structures as well as controls are diverse.

TEs often have mechanisms to counteract silencing by the host. Spm elements in maize spontaneously switch activity between silent and active states, which correlates with changes in DNA methylation status in the UCR (upstream controlling region) and DCR (downstream controlling region). Loss of methylation can be induced by TnpA, a protein encoded by Spm (Schläppi et al. 1994; Cui and Fedoroff 2002). TnpA is able to induce loss of methylation in both the UCR and DCR. Interestingly, deletion of the DCR stabilizes the expression of reporter
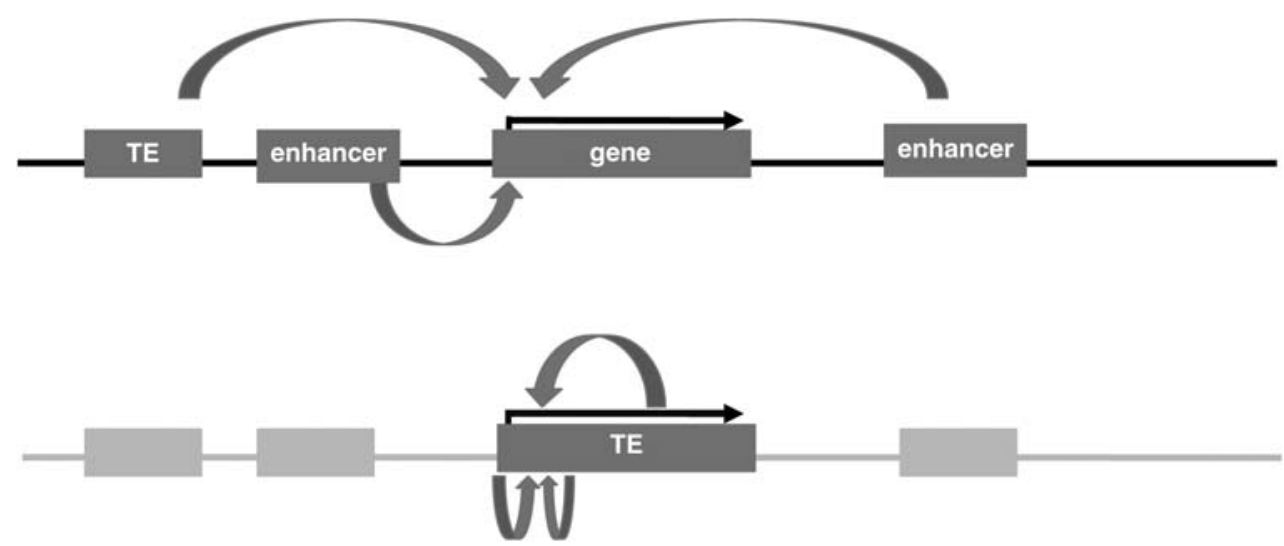

Figure 1. Transcription of a gene can be controlled by cis-acting elements surrounding it, but TEs should keep these cis-acting elements within itself. The gene (top) will evolve to coordinate transcription using surrounding cis-acting elements, some of which are methylation sensitive and even evolved from TEs. The TE (bottom) should evolve to control its transcription using cis elements within itself, because the control should work after transposition to different genomic environments. 


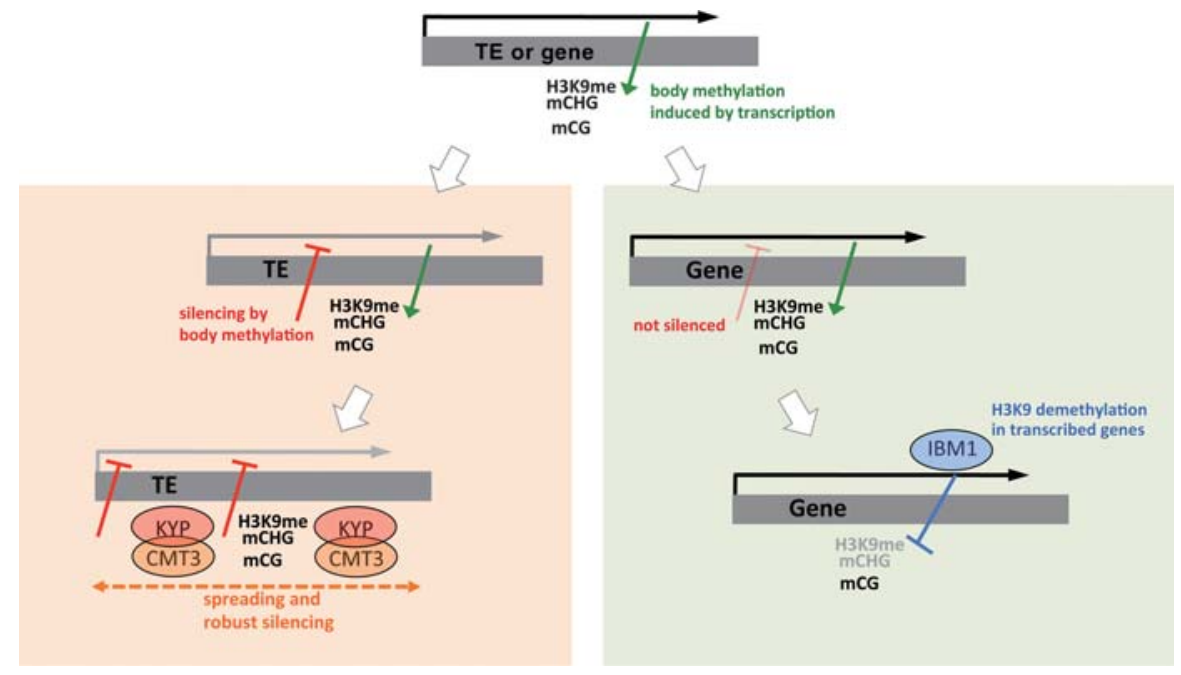

Figure 2. Differentiation of genes and TEs, by differential response to body methylation. For both genes and TEs, transcription of the long transcription unit induces accumulation of DNA methylation and $\mathrm{H} 3 \mathrm{~K} 9 \mathrm{me}$ (green arrow; top panel). Heterochromatin in the body suppresses transcription of the TE (red bar; middle left), but genes are not affected (middle right). In genes, transcription induces loss of H3K9me and CHGme by action of the IBM1 demethylase (blue bar; bottom right). CGme in the gene body does not spread but is maintained by maintenance methylation. In the TE, without function of IBM1, H3K9me and CHGme spread by a positive feedback loop (orange double arrow; bottom left), making the silencing more robust with promoter methylation.

transgenes (Schläppi et al. 1994). The DCR, which is localized within the transcribed region, mediates the silencing, most likely by controlling epigenetic states.

Mutator is another transposon characterized well in maize. Reversible change in Mutator activity correlates with DNA methylation in terminal regions as well as internal regions (Chandler and Walbot 1986; Brown and Sundaresan 1992). Silent Mutator can be activated sporadically by the mopl mutation. The MOP1 gene encodes a protein similar to Arabidopsis RDR2 (RNA-dependent RNA polymerase 2), which is involved in RdDM (Lisch et al. 2002; Alleman et al. 2006). In Arabidopsis, mutations in RdDM components generally affect terminal regions of long TEs. Methylation in terminal regions may be important for maize Mutator elements. Interestingly, however, although the mopl mutation causes loss of methylation in the terminal regions immediately, expression of mudrA occurs progressively, possibly reflecting additional epigenetic factor(s) in addition to the DNA methylation in the terminal regions (Lisch et al. 2002). It would be interesting to learn if heterochromatin in the internal region is involved.

\section{PERSPECTIVE}

We propose that TEs could be specifically silenced by the mechanism to accumulate epigenetic marks within transcribed regions (Fig. 2, top). Dependence of heterochromatin formation on transcription has been suggested in a fission yeast Schizosaccharomyces pombe. In $S$. pombe, a mutant allele of Pol II causes a defect in silencing (Kato et al. 2005). In plants, a transcript of Pol V that is related to Pol II is suggested to form a scaffold for silencing machinery (Wierzbicki et al. 2008, 2009).
Another key feature in the model is the positive feedback loop between CHGme and H3K9me that causes spreading of heterochromatin from the body to the promoter. The H3K9 methyltransferase KYP/SUVH4 has an SRA domain that recognizes CHGme (Johnson et al. 2007). Mutations in the KYP/SUVH4 gene suppress the ibml-induced increase in $\mathrm{H} 3 \mathrm{~K} 9$ me almost completely (Inagaki et al. 2010). However, in the kyp/suvh4 mutant, $\mathrm{H} 3 \mathrm{~K} 9$ me reduction of endogenous TEs is not complete (Inagaki et al. 2010), suggesting that other H3K9 methyltransferases may be involved. Some H3K9 methyltransferases are suggested to be regulated by DNA methylation in contexts other than CHG (Johnson et al. 2008). These interactions might mediate the simultaneous accumulation of CG and non-CG methylation in the body of transcribed sequences (Fig. 2, top). Although IBM1 excludes H3K9me and DNA methylation at non-CG sites, methylation in CG sites is retained by maintenance methylation catalyzed by MET1 (Fig. 2, bottom right).

The accumulation of both CGme and CHGme are mainly found in long transcription units. Such mechanisms, which would be efficient for silencing long TEs, would probably complement RNAi-based mechanisms that function mainly on short TEs. Although silencing of long TEs tends to be stable and constitutive, control of short TEs could be more dynamic. DNA demethylation in short TEs occurs during development. Genome-wide loss of DNA methylation is found in endosperm and pollen vegetative cells (Gehring et al. 2009; Hsieh et al. 2009; Slotkin et al. 2009; Schoft et al. 2011; Calarco et al. 2012; Ibarra et al. 2012). In those companion cells of germlines, loss of methylation mainly occurs in short TEs. Long TEs lose methylation only in terminal regions and internal regions remain methylated (Ibarra et al. 2012). Again, the length seems a critical parameter. 
We still do not know the exact nature of interactions among various epigenetic marks, some of which are dynamic whereas others are stable. The ibml mutation affects long transcription units and the effects of this mutation become stronger after repeated self-pollinations (Saze et al. 2008). H3K9 demethylation of transcribed genes (Fig. 2, bottom right) may occur in a specific developmental window. It would be interesting to learn how short-term effects of epigenetic changes can be converted to long-term effects.

\section{ACKNOWLEDGMENTS}

We thank Fred Berger, Rob Martienssen, Marjori Matzke, and Craig Pikaard for comments on the manuscript.

\section{REFERENCES}

Alleman M, Sidorenko L, McGinnis K, Seshadri V, Dorweiler JE, White J, Sikkink K, Chandler VL. 2006. An RNA-dependent RNA polymerase is required for paramutation in maize. Nature 442: 295-298.

Brown J, Sundaresan V. 1992. Genetic study of the loss and restoration of Mutator transposon activity in maize: Evidence against dominant-negative regulator associated with loss of activity. Genetics 130: 889-898.

Calarco JP, Borges F, Donoghue MTA, Van Ex F, Jullien PE, Lopes T, Gardner R, Berger F, Feijo JA, Becker JD, et al. 2012. Reprogramming of DNA methylation in pollen guides epigenetic inheritance via small RNA. Cell 151: 194-205.

Chan SW, Henderson IR, Jacobsen SE. 2005. Gardening the genome: DNA methylation in Arabidopsis thaliana. Nat Rev Genet 6: 351-360.

Chandler V, Walbot V. 1986. DNA modification of a maize transposable element correlates with loss of activity. Proc Natl Acad Sci 83: 1767-1771.

Cokus SJ, Feng S, Zhang X, Chen Z, Merriman B, Haudenschild CD, Pradhan S, Nelson SF, Pellegrini M, Jacobsen SE. 2008. Shotgun bisulphite sequencing of the Arabidopsis genome reveals DNA methylation patterning. Nature 452: 215-219.

Coleman-Derr D, Zilberman D. 2012. Deposition of histone variant $\mathrm{H} 2 \mathrm{~A} . \mathrm{Z}$ within gene bodies regulated responsive genes. PLoS Genet 8: e1002988.

Cui H, Fedoroff NV. 2002. Inducible DNA demethylation mediated by the maize Suppressor-mutator transposon-encoded TnpA protein. Plant Cell 14: 2883-2899.

Fujimoto R, Kinoshita Y, Kawabe A, Kinoshita T, Takashima K, Nordborg M, Nasrallah ME, Shimizu KK, Kudoh H, Kakutani T. 2008. Evolution and control of imprinted genes in the genus Arabidopsis. PLoS Genet 4: e10000048.

Gehring M, Bubb KL, Henikoff S. 2009. Extensive demethylation of repetitive elements during seed development underlies gene imprinting. Science 324: 1447-1451.

Grewal SI, Elgin SC. 2007. Transcription and RNA interference in the formation of heterochromatin. Nature 447: 399-406.

Haag JR, Pikaard CS. 2011. Multisubunit RNA polymerases IV and V: Purveyors of non-coding RNA for plant gene silencing. Nat Rev Mol Cell Biol 12: 483-492.

Henderson IR, Jacobsen SE. 2008. Tandem repeats upstream of the Arabidopsis endogene SDC recruit non-CG DNA methylation and initiate siRNA spreading. Genes Dev 22: $1597-$ 1606.

Henderson IR, Deleris A, Wong W, Zhong X, Chin HG, Horwitz GA, Kelly KA, Pradhan S, Jacobsen SE. 2010. The de novo cytosine methyltransferase DRM2 requires intact UBA domains and a catalytically mutated paralog DRM3 during
RNA-directed DNA methylation in Arabidopsis thaliana. PLoS Genet 6: e1001182.

Herr AJ, Jensen MB, Dalmay T, Baulcombe DC. 2005. RNA polymerase IV directs silencing of endogenous DNA. Science 308: $118-120$.

Hsieh TF, Ibarra CA, Silva P, Zemach A, Eshed-Williams L, Fischer RL, Zilberman D. 2009. Genome-wide demethylation of Arabidopsis endosperm. Science 324: 1451-1454.

Huettel B, Kanno T, Daxinger L, Aufsatz W, Matzke AJM, Matzke M. 2006. Endogenous targets of RNA-directed DNA methylation and PolIV in Arabidopsis. EMBO J 25: 28282836.

Ibarra CA, Feng X, Schoft VK, Hsieh T-F, Uzawa R, Rodrigues JA, Zemach A, Chumak N, Machlicova A, Nishimura T, et al. 2012. Active DNA demethylation in plant companion cells reinforces transposon methylation in gametes. Science 337: $1360-1364$.

Inagaki S, Miura A, Nakamura K, Lu F, Cui X, Cao X, Kimura H, Saze H, Kakutani T. 2010. Autocatalytic differentiation of epigenetic modifications within the Arabidopsis genome. EMBO J 29: 3496-3506.

Jackson JP, Lindroth AM, Cao X, Jacobsen SE. 2002. Control of CpNpG DNA methylation by the KRYPTONITE histone H3 methyltransferase. Nature 416: 556-560.

Johnson LM, Bostick M, Zhang X, Kraft E, Henderson I, Callis J, Jacobsen SE. 2007. The SRA methyl-cytosine-binding domain links DNA and histone methylation. Curr Biol 17: 379-384.

Johnson LM, Law JA, Khattar A, Henderson I, Jacobsen SE. 2008. SRA-domain proteins required for DRM2-mediated de novo methylation. PLoS Genet 4: e1000280.

Kakutani T, Kato M, Kinoshita T, Miura A. 2004. Control of development and transposon movement by DNA methylation in Arabidopsis thaliana. Cold Spring Harb Symp Quant Biol 69: $139-143$.

Kato H, Goto DB, Martienssen RA, Urano T, Furukawa K, Murakami Y. 2005. RNA polymerase II is required for RNAidependent heterochromatin assembly. Science 309: 467-469.

Kinoshita T, Miura A, Choi Y, Kinoshita Y, Cao X, Jacobsen SE, Fischer RL, Kakutani T. 2004. One-way control of FWA imprinting in Arabidopsis endosperm by DNA methylation. Science 303: $521-523$.

Law JA, Jacobsen SE. 2010. Establishing, maintaining and modifying DNA methylation patterns in plants and animals. Nat Rev Genet 11: 204-220.

Lee TF, Gurazada SG, Zhai J, Li S, Simon SA, Matzke MA, Chen X, Meyers BC. 2012. RNA polymerase V-dependent small RNAs in Arabidopsis originate from small, intergenic loci including most SINE repeats. Epigenetics 7: 781-795.

Lippman Z, Martienssen RA. 2004. The role of RNA interference in heterochromatic silencing. Nature 431: 364.

Lippman Z, Gendrel AV, Black M, Vaughn MW, Dedhia N, McCombie WR, Lavine K, Mittal V, May B, Kasschau KD, et al. 2004. Role of transposable elements in heterochromatin and epigenetic control. Nature 430: 471-476.

Lisch D, Carey CC, Dorweiler JE, Chandler VL. 2002. A mutation that prevents paramutation in maize also reverses Mutator transposon methylation and silencing. Proc Natl Acad Sci 99: 6130-6135.

Lister R, O'Malley RC, Tonti-Filippini J, Gregory BD, Berry CC, Millar AH, Ecker JR. 2008. Highly integrated single-base resolution maps of the epigenome in Arabidopsis. Cell 133: $523-536$.

Malagnac F, Bartee L, Bender J. 2002. An Arabidopsis SET domain protein required for maintenance but not establishment of DNA methylation. EMBO J 21: 6842-6852.

Martienssen RA. 2003. Maintenance of heterochromatin by RNA interference of tandem repeats. Nat Genet 35: 213-214.

Matzke M, Kanno T, Daxinger L, Huettel B, Matzke AJ. 2009. RNA-mediated chromatin-based silencing in plants. Curr Opin Cell Biol 21: 367-376.

Mette MF, Aufsatz W, van der Winden J, Matzke MA, Matzke AJ. 2000. Transcriptional silencing and promoter methylation 
triggered by double-stranded RNA. EMBO J 19: 5194-5201.

Mirouze M, Reinders J, Bucher E, Nishimura T, Schneeberger K, Ossowski S, Cao J, Weigel D, Paszkowski J, Mathieu O. 2009. Selective epigenetic control of retrotransposition in Arabidopsis. Nature 461: 427-430.

Miura A, Nakamura M, Inagaki S, Kobayashi A, Saze H, Kakutani T. 2009. An Arabidopsis jmjC domain protein protects transcribed genes from DNA methylation at $\mathrm{CHG}$ sites. EMBO J 28: 1078-1086.

Saze H, Kakutani T. 2007. Heritable epigenetic mutation of a transposon-flanked Arabidopsis gene due to lack of the chromatin-remodeling factor DDM1. EMBO J 26: 3641.

Saze H, Kakutani T. 2011. Differentiation of epigenetic modifications between transposons and genes. Curr Opin Plant Biol 14: 81-87.

Saze H, Shiraishi A, Miura A, Kakutani T. 2008. Control of genic DNA methylation by a jmjC domain-containing protein in Arabidopsis thaliana. Science 319: 462-465.

Schläppi M, Raina R, Fedoroff N. 1994. Epigenetic regulation of the maize Spm transposable element: Novel activation of a methylated promoter by TnpA. Cell 77: 427-437.

Schoft VK, Chumak N, Choi Y, Hannon M, Garcia-Aguilar M, Machlicova A, Slusarz L, Mosiolek M, Park JS, Park GT, et al. 2011. Function of the DEMETER DNA glycosylase in the Arabidopsis thaliana male gametophyte. Proc Natl Acad Sci 108: 8042-8047.

Slotkin RK, Vaughn M, Borges F, Tanurdzic M, Becker JD, Feijo JA, Martienssen RA. 2009. Epigenetic reprogramming and small RNA silencing of transposable elements in pollen. Cell 136: $461-472$.

Soppe WJ, Jacobsen SE, Alonso-Blanco C, Jackson JP, Kakutani T, Koornneef M, Peeters AJ. 2000. The late flowering phenotype of fwa mutants is caused by gain-of-function epigenetic alleles of a homeodomain gene. Mol Cell 6: 791-802.

Takuno S, Gaut BS. 2012. Body methylated genes in Arabidopsis thaliana are functionally important and evolve slowly. Mol Biol Evol 29: 219-227.

Tran RK, Zilberman D, de Bustos C, Ditt RF, Henikoff JG, Lindroth AM, Delrow J, Boyle T, Kwong S, Bryson TD, et al. 2005. Chromatin and siRNA pathways cooperate to maintain DNA methylation of small transposable elements in Arabidopsis. Genome Biol 6: R90.

Tsukahara S, Kobayashi A, Kawabe A, Mathieu O, Miura A, Kakutani T. 2009. Bursts of retrotransposition reproduced in Arabidopsis. Nature 461: 423-426.

Wasseneger M, Heimes S, Riedel L, Stanger HL. 1994. RNAdirected de novo methylation of genomic sequences in plants. Cell 76: 567-576.

Wierzbicki AT, Haag JR, Pikaard CS. 2008. Noncoding transcription by RNA polymerase Pol IVb/Pol V mediates transcriptional silencing of overlapping and adjacent genes. Cell 135: $635-648$.

Wierzbicki AT, Ream TS, Haag JR, Pikaard CS. 2009. RNA polymerase $\mathrm{V}$ transcription guides ARGONAUTE4 to chromatin. Nat Genet 41: 630-634.

Xie Z, Johansen LK, Gustafson AM, Kasschau KD, Lellis AD, Zilberman D, Jacobsen SE, Carrington JC. 2004. Genetic and functional diversification of small RNA pathways in plants. Curr Biol 14: 1214-1220.

Zhang X, Yazaki J, Sundaresan A, Cokus S, Chan SW, Chen H, Henderson IR, Shinn P, Pellegrini M, Jacobsen SE, et al. 2006. Genome-wide high-resolution mapping and functional analysis of DNA methylation in Arabidopsis. Cell 126: 1189-1201.

Zhong X, Hale CJ, Law JA, Johnson LM, Feng S, Tu A, Jacobsen SE. 2012. DDR complex facilitates global association of RNA polymerase $\mathrm{V}$ to promoters and evolutionarily young transposons. Nat Struct Mol Biol 19: 870-875.

Zilberman D, Cao X, Johansen LK, Xie Z, Carrington JC, Jacobsen SE. 2004. Role of Arabidopsis ARGONAUTE4 in RNAdirected DNA methylation triggered by inverted repeats. Curr Biol 14: 1214-1220.

Zilberman D, Gehring M, Tran RK, Ballinger T, Henikoff S. 2007. Genome-wide analysis of Arabidopsis thaliana DNA methylation uncovers an interdependence between methylation and transcription. Nat Genet 39: 61-69.

Zilberman D, Coleman-Derr D, Ballinger T, Henikoff S. 2008. Histone H2A.Z and DNA methylation are mutually antagonistic chromatin marks. Nature 456: 125-129. 


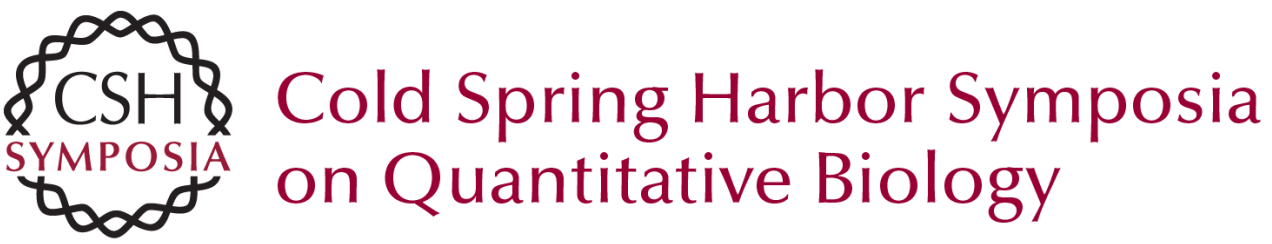

\section{What Triggers Differential DNA Methylation of Genes and TEs: Contribution of Body Methylation?}

S. Inagaki and T. Kakutani

Cold Spring Harb Symp Quant Biol 2012 77: 155-160 originally published online January 9, 2013 Access the most recent version at doi:10.1101/sqb.2013.77.016212

References This article cites 56 articles, 16 of which can be accessed free at: http://symposium.cshlp.org/content/77/155.full.html\#ref-list-1

License

Email Alerting Receive free email alerts when new articles cite this article - sign up in Service the box at the top right corner of the article or click here. 